\title{
Analysis of Cardiovascular Fitness, Sleep Quality, Depression, Fatigue, and Quality of Life among Individuals with Respect to the Glycated Hemoglobin Level in Type 2 Diabetes Mellitus
}

\author{
Swetank Pathak Shweta Shenoy \\ MYAS - GNDU Department of Sports Science and Medicine, Guru Nanak Dev University, Amritsar, India
}

\section{Keywords}

Diabetes · Sleep · Depression · Glycated hemoglobin .

Duration

\begin{abstract}
Background: Diabetes as a metabolic disorder can affect the various systems of the body, resulting in a decrease in cardiovascular fitness, sleep quality, and life quality that can lead to depression and fatigue. Aim: We analyzed cardiovascular fitness, sleep quality, depression, fatigue, and quality of life among individuals with a glycated hemoglobin (HBA1C) level $>6.5 \%$ and $\leq 6.5 \%$, as well as the relationship among glycated hemoglobin, maximal oxygen consumption $\left(\mathrm{VO}_{2} \mathrm{max}\right)$, obesity, sleep quality, depression, and duration of diabetes. Method: HBA1C (mean: $5.90 \pm 0.93 \%$ ) was studied in a total of 70 subjects (mean age: $62.37 \pm 7.5$ years). The 2 study groups were as follows: group $A, \mathrm{HBA} 1 \mathrm{C}>6.5 \%$, and group $\mathrm{B}, \mathrm{HBA} 1 \mathrm{C} \leq 6.5 \%$. $\mathrm{BMI}, \mathrm{VO}_{2} \max$, quality of sleep and life, depression, and fatigue were assessed in both groups. Results: There was a statistically significant difference between the groups at a significance level of $p<0.001$. Group A had a lower cardiovascular fitness, a poor sleep quality, and increased depression compared to group B. A statistically significant negative linear correlation was found between $\mathrm{VO}_{2}$ max and glycated hemoglobin, and a significant positive linear correlation was found between glycated he-
\end{abstract}

\begin{tabular}{ll}
\hline KARGER & $\begin{array}{l}\text { (c) } 2019 \text { The Author(s) } \\
\text { Published by S. Karger AG, Basel }\end{array}$ \\
E-Mail karger@karger.com & $\begin{array}{l}\text { This article is licensed under the Creative Commons Attribution- } \\
\text { NonCommercial-NoDerivatives 4.0 International License (CC BY- } \\
\text { NC-ND) (http://www.karger.com/Services/OpenAccessLicense). } \\
\text { Usage and distribution for commercial purposes as well as any dis- } \\
\text { tribution of modified material requires written permission. }\end{array}$
\end{tabular}

moglobin and duration of diabetes, poor quality of sleep, and depression for all subjects, which was insignificant in the groups. Conclusions: A long duration of diabetes and an increased glycemic status may influence cardiovascular fitness, sleep quality, and life quality, leading to depression and fatigue.

(c) 2019 The Author(s)

Published by S. Karger AG, Basel

\section{Introduction}

The World Health Organization (WHO) has defined diabetes as a metabolic endocrine disorder characterized by chronic hyperglycemia with disorders of carbohydrate, fat, and protein metabolism occurring as a result of deficiencies in insulin secretion, insulin action, or both [1]. As per a WHO report, in 2016 around 422 million adult individuals were affected with diabetes worldwide. In 2014, the global prevalence rate in the adult population almost doubled, i.e., from $4.7 \%$ in 1980 to $8.5 \%$ in 2014 [2]. One of the fastest growing chronic disease in the world is diabetes mellitus and India is considered to be the "diabetes capital of the world" as it is home to an estimated 46 million diabetic people [3].

In patients with type 2 diabetes mellitus (T2DM) cardiovascular disease (CVD) is the most common complication. CVD related to early death in T2DM individuals 
has a higher prevalence rate than CVD without T2DM [4]. It has been noted that insulin resistance is the chief cause of T2DM and it further affects the fate of cardiovascular physiology resulting in CVD [5]. There is a 15-20\% decrease in severe cardiovascular events when there is a $1 \%$ absolute decline in the HBA1C value [6].

Variation of cardiovascular function with sleep duration has been demonstrated by increased blood pressure [7]. An association has been reported between difficulty initiating sleep and the risk of prediabetes [8]. High fasting plasma glucose and high $\mathrm{HBA} 1 \mathrm{C}$ are related to both short and long durations of sleep [9].

Social and personal functioning have also been affected and credited with causing T2DM [10]. Poor metabolic control has also been associated with depression $[11,12]$, which results in more complications and a worse healthrelated quality of life in T2DM [13]. Alteration in the daily life routine result in poor compliance with respect to monitoring and treatment and a reduced adherence to the diet, which has been suggested as a possible factor for the relationship between depression and glycemic control in T2DM [14].

Individuals with T2DM are constantly challenged by their disease and its daily supervision demands. Diabetics deal with their condition on a daily basis, having to make many decisions in regularly futile efforts to achieve a nondiabetic metabolic state [15].

The sedentary lifestyle and low levels of physical activity seen in diabetic individuals cause obesity and affect cardiorespiratory fitness; dietary habit modification and medication in diabetic individuals have a profound effect, resulting a poor sleep quality, depression, fatigue, and a diminished quality of life. Thus, an analysis of cardiovascular fitness, sleep quality, depression, fatigue, and quality of life is needed. The aim of the present study was to analyze the cardiovascular fitness, sleep quality, depression, fatigue, and quality of life of individuals with a glycated hemoglobin level $>6.5 \%$ and $\leq 6.5 \%$.

\section{Materials and Methods}

\section{Methods}

The subjects of this nonrandomized, single-group observational study with a sample size of 70 were divided into the following 2 groups: group A $(n=19)$, comprised of participants with an HBA $1 C$ value $>6.5 \%$, and group B $(n=51)$, comprised of participants with an HBA1C value $\leq 6.5 \%$; all of the enrolled participants took part in the study. This study was completed at the MYAS GNDU - Department of Sport Science and Medicine, Guru Nanak Dev University, with data collection between March 2018 and November 2018.

\section{Participants}

Participants were recruited from the outpatient department of the health center of Guru Nanak Dev University, Amritsar, India, through screening. The inclusion criteria were: type 2 diabetes, age $55-75$ years, fasting blood glucose $>126 \mathrm{mg} / \mathrm{dL}$, and a history of diabetes of 5 years or longer. Participants were excluded from this study if they: were aged over 75 years; had a history of vestibular, peripheral vascular, neurological (other than of a diabetic etiology), or rheumatic disease; had a visual acuity $<6 / 18$ of any etiology; had regular use of centrally acting medications; had had any major or minor amputation; or had any previous illness or operation that could interfere in any way with the measurements.

The following analyses were done: glucose level; measurement of height, weight, and BMI; the 6-min walk test; a subjective examination (via a questionnaire) of sleep on the Pittsburgh Sleep Quality Index (PSQI), fatigue on the multidimensional fatigue inventory-20, depression on the Patient Health Questionnaire-9 (PHQ-9), and quality of life on the WHOQOL. These analyses were conducted on same day between 9:00 and 11:00 a.m. and between 3:00 and 5:00 p.m. There were no changes in the dietary habits or activities of daily living of the participants during this study.

Glycated hemoglobin, fasting blood glucose, and oral glucose tolerance test results were analyzed and documented through blood laboratory reports provided by participants upon enrollment into this study. The 6-min walk test is a submaximal measure of aerobic capacity that was used to assess cardiovascular fitness. The maximum oxygen consumption was evaluated via the 6-min walk test using the following formula: $\mathrm{VO}_{2} \max =0.03 \times$ distance (in $\mathrm{m})+3.98$ [16]. The BMI was used to analyze the body composition; obesity was determined based on the BMI according to the following formula: $\mathrm{BMI}=$ weight $($ in $\mathrm{kg}) /(\text { height }[\text { in } \mathrm{m}])^{2}$. Sleep quality was assessed using the PSQI on a scale of 0 (very good) to 3 (very bad). It has been found to be a reliable and valid measure of sleep disturbances in a wide range of people $[17,18]$. The PHQ9 was used to measure the depression rate on a scale of 0 (not at all) to 3 (nearly every day). This scale has also been found to be a reliable and valid measure of depression severity in a wide range of people [19]. The Multidimensional Fatigue Inventory was used to analyze central fatigue on a Likert scale; general fatigue, physical fatigue, mental fatigue, reduced motivation, and reduced activity are 5 subscales comprising 20 statements. The reliability and validity of this inventory have been established in people with cancer and chronic fatigue syndrome, and this inventory has been used in previous studies of fatigue in persons with diabetes $[20,21]$. The WHO Quality of Life-BREF was used to measure quality of life on a scale of 1 to 5 . This scale has been found to be a reliable and valid measure of quality of life in a wide range of people [22].

\section{Statistical Analysis}

All data were analyzed using Microsoft Office Excel 2010 and SPSS 21.0. The normality of the data was assessed using the Kolmogorov-Smirnov test in SPSS 21.0 Descriptive statistics were calculated and Student independent $t$ tests were used to compare means between the groups for the following parameters: BMI, duration of diabetes, maximal oxygen consumption $\left(\mathrm{VO}_{2} \mathrm{max}\right)$, sleep quality, depression, fatigue, and quality of life. Glycated hemoglobin was correlated with $\mathrm{VO}_{2}$ max, duration of diabetes, BMI, sleep, depression, and quality of life, using Pearson's correlation test. 
Table 1. Descriptive statistics

\begin{tabular}{lccc}
\hline Variables & $\begin{array}{l}\text { Total participants } \\
(n=70)\end{array}$ & $\begin{array}{l}\text { Group A participants } \\
(n=19)\end{array}$ & $\begin{array}{l}\text { Group B participants } \\
(n=51)\end{array}$ \\
\hline Age, years & $62.37 \pm 7.5$ & $58.74 \pm 5.29$ & $63.73 \pm 7.79$ \\
Weight, kg & $72.90 \pm 9.56$ & $82.74 \pm 11.45$ & $69.24 \pm 5.34$ \\
Height, cm & $170.40 \pm 6.37$ & $171.84 \pm 4.9$ & $169.87 \pm 6.8$ \\
BMI & $25.12 \pm 3.09$ & $27.94 \pm 3.04$ & $24.07 \pm 2.39$ \\
HBA1C, \% & $5.90 \pm 0.93$ & $7.16 \pm 0.69$ & $5.4 \pm 0.46$ \\
Fasting blood sugar, mg/dL & $143.17 \pm 15.87$ & $155.53 \pm 18.7$ & $138.57 \pm 11.94$ \\
Oral glucose tolerance test result, & $182.54 \pm 24.07$ & $192.47 \pm 22.8$ & $178.84 \pm 23.68$ \\
$\quad$ mg/dL & $6.81 \pm 2.26$ & & \\
Duration of diabetes, years & & $9.1 \pm 2.23$ & $5.9 \pm 1.6$ \\
\hline
\end{tabular}

Values are presented as means \pm SD. Group A had HBA1C $>6.5 \%$ HBA1C and group B had HBA $1 \mathrm{C} \leq 6.5 \%$.

Table 2. Comparison between groups $A$ and $B$

\begin{tabular}{lccc}
\hline Variables & Group A & Group B & $p$ value \\
\hline BMI & $27.94 \pm 3.04$ & $24.07 \pm 2.39$ & $<0.001^{* *}$ \\
Duration of diabetes, years & $9.1 \pm 2.23$ & $5.9 \pm 1.6$ & $<0.001^{* *}$ \\
VO 2 max & $19.97 \pm 2.32$ & $24.70 \pm 2.16$ & $<0.001^{* *}$ \\
PSQI & $6.10 \pm 1.15$ & $3.76 \pm 1.61$ & $<0.001^{* *}$ \\
PHQ-9 & $8.10 \pm 3.21$ & $4.84 \pm 2.11$ & $<0.001^{* *}$ \\
MFI & & & 0.525 \\
$\quad$ General fatigue & $10.36 \pm 2.1$ & $10.72 \pm 1.75$ & 0.634 \\
$\quad$ Physical fatigue & $11.84 \pm 1.34$ & $12.01 \pm 1.45$ & 0.052 \\
Mental fatigue & $9.78 \pm 1.5$ & $10.66 \pm 1.72$ & 0.146 \\
Reduced activity & $11.31 \pm 2.8$ & $12.37 \pm 1.9$ & 0.589 \\
$\quad$ Reduced motivation & $13.05 \pm 2.09$ & $12.76 \pm 1.53$ & 0.588 \\
WHO quality of life & & & 0.545 \\
$\quad$ Physical score & $66.47 \pm 9.64$ & $67.92 \pm 10.42$ & $<0.05^{*}$ \\
$\quad$ Psychological score & $59.05 \pm 8.72$ & $57.05 \pm 7.52$ & 0.852 \\
Social score & $78.36 \pm 9.4$ & $84.62 \pm 11.70$ & $78.68 \pm 6.13$ \\
$\quad$ Environmental score & $79.05 \pm 7.59$ & & \\
\hline
\end{tabular}

Values are presented as means \pm SD. MFI, Multidimensional Fatigue Index-20. ** Highly significant; * significant

\section{Results}

The demographic characteristics, glycated hemoglobin, fasting blood glucose, oral glucose tolerance test results, and duration of diabetes of the participants are presented in Table 1. Comparisons between groups were done using Student's independent $t$ test (Table 2).

So, it can be stated that in both groups there were the differences in $\mathrm{BMI}, \mathrm{VO}_{2} \mathrm{max}$, sleep quality, depression, duration of diabetes, and social score; other parameters were insignificant.

Table 3 shows the correlation of glycated hemoglobin with $\mathrm{VO}_{2} \mathrm{max}, \mathrm{BMI}$, sleep quality, depression, and duration of diabetes in type 2 diabetic participants. There was a statistically significant negative correlation between glycated hemoglobin and $\mathrm{VO}_{2} \max (r=-0.602, p=<0.01)$, a significant positive correlation between glycated hemoglobin and BMI $(r=0.533, p=<0.01)$, a significant posi- 
Table 3. Correlation of $\mathrm{HBA} 1 \mathrm{C}$ with $\mathrm{VO}_{2} \mathrm{max}$, BMI, sleep quality, depression, and duration of diabetes using Pearson's correlation test

\begin{tabular}{|c|c|c|c|c|c|c|c|c|c|}
\hline \multicolumn{2}{|c|}{$\mathrm{VO}_{2} \max$} & \multicolumn{2}{|l|}{ BMI } & \multicolumn{2}{|c|}{ Sleep quality (PSQI) } & \multicolumn{2}{|c|}{ Depression (PHQ-9) } & \multicolumn{2}{|c|}{ Duration of diabetes } \\
\hline$r$ value & $p$ value & $r$ value & $p$ value & $r$ value & $p$ value & $r$ value & $p$ value & $r$ value & $p$ value \\
\hline$-0.602^{*}$ & $<0.01$ & $0.533^{*}$ & $<0.01$ & $0.491^{*}$ & $<0.01$ & $0.292^{*}$ & $<0.05$ & $0.526^{*}$ & $<0.01$ \\
\hline
\end{tabular}

$* p$ value $<0.01$

Table 4. Statistical analysis of the total participants

\begin{tabular}{llcccrrr}
\hline Parameter & Subjects, & Maximum & Minimum & Total & Range & Mean & SD \\
& $n$ & & & & & & \\
\hline Sleep quality & 70 & 8.00 & 1.00 & 21 & 7.00 & 4.4000 & 1.82 \\
Depression & 70 & 16.00 & 1.00 & 27 & 15.00 & 5.7286 & 2.83 \\
General fatigue & 70 & 14.00 & 7.00 & 20 & 7.00 & 10.6286 & 1.86 \\
Mental fatigue & 70 & 16.00 & 6.00 & 20 & 10.00 & 10.4286 & 1.72 \\
Reduced activity & 70 & 16.00 & 5.00 & 20 & 11.00 & 12.0857 & 2.24 \\
Reduced motivation & 70 & 16.00 & 9.00 & 20 & 7.00 & 12.8429 & 1.69 \\
Physical fatigue & 70 & 14.00 & 10.00 & 20 & 4.00 & 11.9714 & 1.41 \\
Physical score & 70 & 81.00 & 50.00 & 100 & 31.00 & 67.5286 & 10.17 \\
Psychological score & 70 & 75.00 & 44.00 & 100 & 31.00 & 58.0429 & 7.82 \\
Social score & 70 & 100.00 & 69.00 & 100 & 31.00 & 82.9286 & 11.41 \\
Environmental score & 70 & 88.00 & 63.00 & 100 & 25.00 & 78.7857 & 6.50 \\
\hline
\end{tabular}

tive correlation between glycated hemoglobin and sleep quality ( $r=0.491, p=<0.01)$, a significant positive correlation between glycated hemoglobin and depression $(r=0.292, p=<0.05)$, and a significant positive correlation between glycated hemoglobin and duration of diabetes $(r=0.526, p=<0.01)$.

Table 4 shows the range, mean, and SD for the depression, sleep quality, fatigue (subcategorized), and quality of life (subcategorized) scores of the total participants.

\section{Discussion}

Diabetes is a major health issue. This metabolic disorder affecting many systems of the body such as the cardiopulmonary system, the nervous system, and the musculoskeletal system and it induces a poor sleep quality and depression contributing to the decreased quality of life in T2DM individuals.

Here, we tried to determine cardiovascular fitness, depression, sleep quality, fatigue, and quality of life on the basis of glycated hemoglobin. This study analyzed cardio- vascular fitness, depression, sleep quality, fatigue, and quality of life with respect to glycated hemoglobin, favoring the hypothesis that there was a difference between the groups except in fatigue, physical score, psychological score, and an environmental score of WHO quality of life. This study also analyzed the correlation among glycated hemoglobin, $\mathrm{VO}_{2} \max$, obesity, sleep quality, depression, and duration of diabetes. We found that there was a significant correlation among these parameters. The comparison between $\mathrm{HBA} 1 \mathrm{C}>6.5 \%$ and $\mathrm{HBA} 1 \mathrm{C} \leq 6.5 \%$ in the study showed a significant difference between cardiovascular fitness. It was found that patients with HBA1C $>6.5 \%$ had poor cardiovascular fitness. As the level of glucose intolerance increased, there was a decrement in cardiovascular fitness. This could be due to the fact that low level of physical activity induces poor control of diabetes and consequently poor cardiovascular fitness, a sedentary lifestyle, and increased blood glucose. This results in atherosclerotic changes in arteries, specifically the coronary arteries, causing CVD. Meneilly and Elliott [23] reported similar findings, indicating that cardiovascular fitness is influenced by poor glucose control [23]. 
The comparison between HBA $1 \mathrm{C}>6.5 \%$ and $\mathrm{HBA} 1 \mathrm{C}$ $\leq 6.5 \%$ in this study showed a significant difference between sleep quality. It was found that subjects with HBA $1 C>6.5 \%$ had a poor sleep quality. This can be attributed to the fact that the autonomic nervous system controls sleep, and due to a marked increase in blood glucose it affects the nerves, leading to diabetic neuropathy. Social and personal functioning are also affected and were found to causing sleep disturbances in the participants. A number of pathways have been theorized to adversely impact glucose tolerance [24]. First, due to less sleep, there is increased sympathetic nervous system activity as evidenced by increased urinary and plasma catecholamine levels $[25,26]$. Secondly, there is less absorption of cerebral glucose as seen in positron emission tomography [27]. As the brain is a main source of non-insulin-dependent glucose absorption, due to less absorption of glucose in the brain there is a marked increase in glucose in blood [24]. Third, there is a rise in evening cortisol (an insulin antagonist) levels due to less sleep that could compromise insulin sensitivity to peripheral sites [28]. Type 2 diabetes could occur overtime due to insulin resistance and the resulting increased load on $\beta$ cell function.

The comparison between HBA1C $>6.5 \%$ and HBA1C $\leq 6.5 \%$ in this study showed a significant difference in terms of depression. It was found that subjects with HBA1C $>6.5 \%$ were more depressive as the level of glucose and the duration of diabetes increased, and this can be attributed to dietary checks and lifestyle modifications. These mediators help the individual during short-term stress. This hormonal imbalance results in visceral adiposity, which acts in diabetes and CVD via the development of insulin resistance [29]. Few studies have established a link between psychosocial factors and T2DM. Risk factors for T2DM, among the most studied psychological phenotypes, are anxiety, early life traumas, and posttraumatic stress syndrome [30, 31]. Furthermore, personality factors such as the personality traits that were constant and relatively unchanged even in adulthood have been associated with depression $[32,33]$ and with risk factors for T2DM [34].

Both groups showed a insignificant difference for central fatigue, and this can be attributed to the fact that both groups were under psychological stress, making lifestyle modifications, and experiencing concern regarding their health issues.

Additionally, quality of life was also studied and it was found that social life was more affected than physical, psychological, and environmental life. This could be at-

The Relationship among T2DM, $\mathrm{VO}_{2} \max$, and Various Psychological Parameters tributed to the fact that the participants were depressive or had disturbed sleep patterns. Dietary habits, medication, and lifestyle add affect the quality of life. Outcomes related to the quality of life are similar worldwide, and many studies have shown a deterioration of health-related quality of life, mainly implementing low quality of life anxiety and depression [35].

It was also found that the prevalence of obesity was greater in diabetes and as the duration of diabetes increased and there was poor control of glucose. As in obese persons there is a marked increase in fat mass compared to lean mass, there is less utilization of blood glucose, leading to the increased glucose level in the participants. The results were consistent with previous studies indicating the prevalence of obesity, diabetes, and obesity-related health risk factors [36, 37].

The limitation of the present study is that no intervention was provided to check the effect of the same parameters in diabetic individuals. The questionnaire was given to participants and their answers were subjective and may be biased to some extent.

A future suggestion could be that any intervention can be given to participants to see the effects of these parameters among themselves and with exercise.

The clinical implication of the present study is that many diabetic patients were unchecked for these physiological and psychological parameters and sleep quality. Thus, these should be assessed and various therapeutic interventions can be suggested, e.g., counseling, dietary habits check, yoga, relaxation techniques, coping strategies, and aerobic exercise. These can be incorporated to enhance patients mental health, sleep quality, and cardiovascular fitness.

\section{Conclusion}

Diabetic individuals with a higher glycated hemoglobin percentage had an increased duration of diabetes, worse cardiovascular health, more obesity, a poor sleep quality, increased depression, and a poor social life compared to diabetic individuals with a lower glycated hemoglobin percentage. If the percentage of high blood glucose increases there will be a decrease in the $\mathrm{VO}_{2}$ max. Thus, it can be said that low cardiovascular fitness may be due to diabetes. Diabetes can be stated as a factor with detrimental effects on sleep quality and increased depression. Social life was affected more than physical life, psychological life, and environmental life in diabetic individuals. 


\section{Statement of Ethics}

Subjects (or their parents or guardians) gave their written informed consent. The study protocol was approved by the institute's committee on human research. No animals were used in this study.

\section{Disclosure Statement}

The authors have no conflict of interests to declare.

\section{Funding Sources}

This article was funded by any funding agency.

\section{Author Contributions}

All of the authors contributed to this study and the preparation of this paper.

\section{References}

1 Hull S, Chowdhury TA, Mathur R, Robson J. Improving outcomes for patients with type 2 diabetes using general practice networks: a quality improvement project in east London. BMJ Qual Saf. 2014 Feb;23(2):171-6.

2 World Health Organization. Global report on diabetes. Geneva: World Health Organization; 2016.

3 Wild S, Roglic G, Green A, Sicree R, King H. Global prevalence of diabetes: estimates for the year 2000 and projections for 2030. Diabetes Care. 2004 May;27(5):1047-53.

$4 \mathrm{Hu}$ FB, Li TY, Colditz GA, Willett WC, Manson JE. Television watching and other sedentary behaviors in relation to risk of obesity and type 2 diabetes mellitus in women. JAMA. 2003 Apr;289(14):1785-91.

5 Fagot-Campagna A, Balkau B, Simon D, Warnet JM, Claude JR, Ducimetière P, et al. High free fatty acid concentration: an independent risk factor for hypertension in the Paris Prospective Study. Int J Epidemiol. 1998 Oct;27(5):808-13.

6 Selvin E, Marinopoulos S, Berkenblit G, Rami T, Brancati FL, Powe NR, et al. Meta-analysis: glycosylated hemoglobin and cardiovascular disease in diabetes mellitus. Ann Intern Med. 2004 Sep; 141(6):421-31.

7 Lusardi P, Zoppi A, Preti P, Pesce RM, Piazza E, Fogari R. Effects of insufficient sleep on blood pressure in hypertensive patients: a 24-h study. Am J Hypertens. 1999 Jan;12:638

8 Knutson KL, Spiegel K, Penev P, Van Cauter E. The metabolic consequences of sleep deprivation. Sleep Med Rev. 2007 Jun;11(3):16378

9 Hayashino Y, Fukuhara S, Suzukamo Y, Okamura T, Tanaka T, Ueshima H; HIPOP-OHP Research group. Relation between sleep quality and quantity, quality of life, and risk of developing diabetes in healthy workers in Japan: the High-risk and Population Strategy for Occupational Health Promotion (HIPOP-OHP) Study. BMC Public Health. 2007 Jun;7(1): 129.
10 Nakajima H, Kaneita Y, Yokoyama E, Harano S, Tamaki T, Ibuka E, et al. Association between sleep duration and hemoglobin Alc level. Sleep Med. 2008 Oct;9(7):745-52.

11 Peyrot M, Rubin RR. Levels and risks of depression and anxiety symptomatology among diabetic adults. Diabetes Care. 1997 Apr; 20(4):585-90.

12 Lustman PJ, Griffith LS, Gavard JA, Clouse RE. Depression in adults with diabetes. Diabetes Care. 1992 Nov;15(11):1631-9.

13 Hänninen JA, Takala JK, Keinänen-Kiukaanniemi SM. Depression in subjects with type 2 diabetes. Predictive factors and relation to quality of life. Diabetes Care. 1999 Jun;22(6): 997-8.

14 Skinner TC, Channon S, Howells L, Mcevilly A. Diabetes during adolescence. In: Snoek FJ, Skinner TC, eds. Psychology in diabetes care. Chichester: Wiley, 2000.

15 American Diabetes Association. Standards of medical care in diabetes: 2012. Diabetes Care. 2012 Jan;35:S11-63.

16 Cahalin LP, Mathier MA, Semigran MJ, Dec GW, DiSalvo TG. The six-minute walk test predicts peak oxygen uptake and survival in patients with advanced heart failure. Chest. 1996 Aug;110(2):325-32.

17 Buysse DJ, Reynolds CF 3rd, Monk TH, Berman SR, Kupfer DJ. The Pittsburgh Sleep Quality Index: a new instrument for psychiatric practice and research. Psychiatry Res. 1989 May;28(2):193-213.

18 Nishiyama T, Mizuno T, Kojima M, Suzuki S, Kitajima T, Ando KB, et al. Criterion validity of the Pittsburgh Sleep Quality Index and Epworth Sleepiness Scale for the diagnosis of sleep disorders. Sleep Med. 2014 Apr;15(4): 422-9.

19 Li C, Friedman B, Conwell Y, Fiscella K. Validity of the Patient Health Questionnaire 2 (PHQ-2) in identifying major depression in older people. J Am Geriatr Soc. 2007 Apr; 55(4):596-602.
20 Spira AP, Beaudreau SA, Stone KL, Kezirian EJ, Lui LY, Redline S, et al.; Osteoporotic Fractures in Men Study. Reliability and validity of the Pittsburgh Sleep Quality Index and the Epworth Sleepiness Scale in older men. J Gerontol A Biol Sci Med Sci. 2012 Apr;67(4): 433-9.

21 Smets EM, Garssen B, Bonke B, De Haes JC. The Multidimensional Fatigue Inventory (MFI) psychometric qualities of an instrument to assess fatigue. J Psychosom Res. 1995 Apr;39(3):315-25.

22 Yao G, Chung CW, Yu CF, Wang JD. Development and verification of validity and reliability of the WHOQOL-BREF Taiwan version. J Formos Med Assoc. 2002 May;101(5): $342-51$.

23 Meneilly GS, Elliott T. Metabolic alterations in middle-aged and elderly obese patients with type 2 diabetes. Diabetes Care. 1999 Jan; 22(1):112-8.

24 Spiegel K, Knutson K, Leproult R, Tasali E, Van Cauter E. Sleep loss: a novel risk factor for insulin resistance and Type 2 diabetes. J Appl Physiol (1985). 2005 Nov;99(5):200819.

25 Irwin M, Thompson J, Miller C, Gillin JC Ziegler M. Effects of sleep and sleep deprivation on catecholamine and interleukin-2 levels in humans: clinical implications. J Clin Endocrinol Metab. 1999 Jun;84(6):1979-85.

26 Tochikubo O, Ikeda A, Miyajima E, Ishii M. Effects of insufficient sleep on blood pressure monitored by a new multibiomedical recorder. Hypertension. 1996 Jun;27(6):1318-24.

27 Spiegel K, Leproult R, Van Cauter E. Impact of sleep debt on metabolic and endocrine function. Lancet. 1999 Oct;354(9188):14359.

28 Leproult R, Copinschi G, Buxton O, Van Cauter E. Sleep loss results in an elevation of cortisol levels the next evening. Sleep. 1997 Oct; 20(10):865-70.

29 Björntorp P. Visceral fat accumulation: the missing link between psychosocial factors and cardiovascular disease? J Intern Med. 1991 Sep;230(3):195-201. 
30 Agyemang C, Goosen S, Anujuo K, Ogedegbe G. Relationship between post-traumatic stress disorder and diabetes among 105,180 asylum seekers in the Netherlands. Eur J Public Health. 2012 Oct;22(5):658-62.

31 Skilton MR, Moulin P, Terra JL, Bonnet F. Associations between anxiety, depression, and the metabolic syndrome. Biol Psychiatry. 2007 Dec;62(11):1251-7.

32 Jylhä P, Isometsä E. The relationship of neuroticism and extraversion to symptoms of anxiety and depression in the general population. Depress Anxiety. 2006;23(5):281-9.
33 Kendler KS. Major depression and generalised anxiety disorder: same genes,(partly) different environments - revisited. Focus. 2004;168(3):68-425.

34 Jokela M, Elovainio M, Nyberg ST, Tabák AG, Hintsa T, Batty GD, et al. Personality and risk of diabetes in adults: pooled analysis of $5 \mathrm{co}-$ hort studies. Health Psychol. 2014 Dec; 33(12):1618-21.

35 Bazata DD, Robinson JG, Fox KM, Grandy S; SHIELD Study Group. Affecting behavior change in individuals with diabetes: findings from the Study to Help Improve
Early Evaluation and Management of Risk Factors Leading to Diabetes (SHIELD). Diabetes Educ. 2008 Nov-Dec;34(6):102536.

36 Mokdad AH, Ford ES, Bowman BA, Dietz WH, Vinicor F, Bales VS, et al. Prevalence of obesity, diabetes, and obesity-related health risk factors, 2001. JAMA. 2003 Jan;289(1):769.

37 Hossain P, Kawar B, El Nahas M. (2009). Obesity and diabetes in the developing world: a growing challenge. N Engl J Med. 2007 Jan 18; 356(3):213-5. 